\title{
“"USATESTDOWN" A PROPOSAL OF A USABILITY TESTING GUIDE FOR MOBILE APPLICATIONS FOCUSED ON PERSONS WITH DOWN SYNDROME."
}

\author{
Doris Cáliz ${ }^{1}$, Loïc Martínez ${ }^{1}$, Richart Cáliz ${ }^{2}$. \\ ${ }^{1}$ Department ETSIINF, DLSIIS, Madrid Polytechnic University, Campus de \\ Montegancedo 28660, Boadilla del Monte, Madrid, Spain \\ ${ }^{2}$ Department of Computer Sciences FIS Group, National Polytechnic \\ University, Ladrón de Guevara E11-25 y Andalucía Quito, Ecuador
}

\begin{abstract}
The usability testing of mobile applications involving persons with Down syndrome is an issue that has not be comprehensively investigated and there is no single proposal that takes on board all the issues that could be taken into account[1]. This study aims to propose a practical guide "USATESTDOWN" to measure and evaluate the usability of mobile applications focusing on Down syndrome users and their primary limitations. The study starts with an analysis of existing methodologies and tools to evaluate usability and integrates concepts related to inspection and inquiry methods into a proposal. The proposal includes the opinions of experts and representative users; their limitations, the applicability during the development process and the accessibility. This guide is based on the literature review and the author's experience in several workshops where persons with Down syndrome used mobile devices.
\end{abstract}

\section{KEYWORDS}

Usability Testing, Mobile Applications, Cognitive Disability, Down Syndrome, Human Computer Interaction (HCI), Mobile Devices.

\section{INTRODUCTION}

Down syndrome (DS) is a genetic disorder with a worldwide incidence close to one in every 700 births but the risk varies with the mother's age. Persons with DS have impaired cognitive processing, language learning and physical abilities, as well as different personal and social characteristics [11]. Because Persons with DS have special characteristics, they need high levels of usability of the products they use. A usability testing methodology suitable for participants including persons with DS needs to be well designed taking on count their special skills [12].

The International Organization for Standardizations (ISO) bases usability on three main attributes: effectiveness, efficiency and satisfaction. Systems with good usability are easy to learn, efficient, not prone to errors and generate user satisfaction [10].

David C. Wyld et al. (Eds) : ITCS, SIP, CST, ARIA, NLP - 2017

pp. 11-26, 2017. (C) CS \& IT-CSCP 2017

DOI : $10.5121 /$ csit.2017.70302 
Testing products with representative users is a key factor for user-centred design. When such representative users are persons with disabilities the user testing process becomes a challenge and in this case evaluation methods based on heuristics and inspection could not attend the final user needs [3].

Persons Persons with Down syndrome have many difficulties to use the mouse and the keyboard because they have fingers shorter than usual [4]. Multi-touch technology helps to solve this problems when people use devices, such as mouse, keyboard or joystick, and enables users to take advantage of the direct manipulation interaction and the benefits of direct touch [9]. There are a big range of functional abilities in individuals with Down syndrome, related to the extent of impairment in the sensory and motor channels [5], memory, and cognition and communication skills [6]. These sensory and motor issues would need to be taken into consideration when researchers want to evaluate a mobile application in individuals with Down syndrome.

The authors have performed a detailed research on articles related with this topic and they have not found a guide to support the usability testing process for mobile applications focused on persons with Down syndrome [7]. After that, they they have evaluated the use of a tool called "Gestures" by a group of 100 persons with DS. The goal was to analyse the skills of these persons to perform basic gestures [8]. The authors found that DS children 5 to 10 year-old are able to perform most of the evaluated multi-touch gestures with success rates close to 100 per cent. This research study is designed to be a preliminary investigation of how users with Down syndrome could potentially utilize touch-screens gestures tasks to obtain a sense of some of the potential challenges to effective use of tablet computers for this population and to investigate how usability testing involving Persons with Down syndrome could be effectively performed. [9].The result of combining the literature review and the research experience in several workshops is the guide to perform usability testing when the participants are persons with DS. This guide is called "USATESTDOWN".

\section{Where is USATESTDOWN}

In the Human Computer Interaction area one of the most commonly used design philosophies to create high quality products for users is the User-Centred Design (UCD) approach [2] UCD refers to the philosophy that the intended user of a product should always be in the centred of the design process throughout all phases of the design [3]. Usability testing, according to Dumas \& Redish [4], aims to achieve the following five goals, to: Improve the product's usability, Involve real users in the testing, give the users real tasks to accomplish, Enable testers to observe and record the actions of the participants, Enable testers analyse the data obtained and make changes accordingly. USATESTDOWN is inside Evaluate the Design Requirements as we can see in Fig 1. 


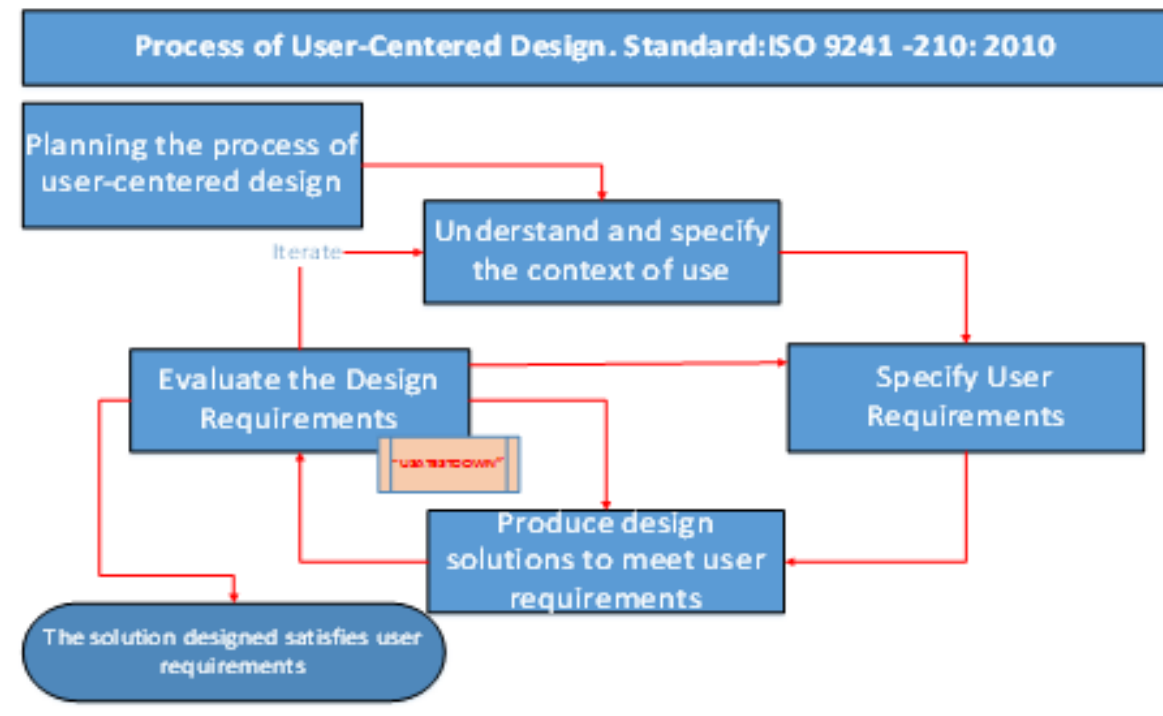

Figure 1: Process of User Centred Design.

\section{RELATED WORK}

\subsection{Usability evaluation methods}

There are three types of usability evaluation methods: observational, analytical and inquiry evaluation methods [5]. Evaluation methods that collect data by observing users' experiences with a product are called observational evaluation methods. Usability testing, user-oriented view and user performance testing are types of observational evaluation methods [6]. Methods that do not collect data from users' experiences but rely on the opinion of experts are called inspection or analytical evaluation methods. These methods have a product-oriented view. Examples of analytical evaluation methods are Heuristic Evaluation [7] Cognitive Walkthrough and Semiotic Inspection [8]. Inquiry methods have a user-oriented view. Inquiry methods tend to identify broad usability problems or opinions about a product as a whole such as user Satisfaction Questionnaires and Focus Groups [9].

\section{Usability Evaluation methods for mobile applications focused on persons with Down syndrome}

While there is some related research, it is incomplete. Devan does not consider mobile or touch screen devices. The author used an application called JECRIPE, this application works in a PC. Additionally it is not a Usability Testing Guide [10]. Kumin and Lazar did a usability evaluation to understand potential interface improvements and they suggest different tips to evaluate usability but it is not a Usability Test guide [11]. AR BACA SindD is a usability evaluation framework for an augmented reality framework for learners with DS but they did a specific evaluation in AR Systems but it is not a Usability test guide [12]. Adebesin, Kotzé show the important role of two evaluation methods in the usability [13]. The authors did not speak about touch screen, usability guide etc. (MEL-SindD) discusses the usability assessment of the courseware but it is not focus on mobile applications [14]. 


\subsection{Working Method Overview}

The guide reproduces the usual usability testing steps. The guide provides recommendations taking into account the needs of people with DS in the usability testing process.

In general, the working method has four main phases, as shown in Fig. 2. The process is iterative.

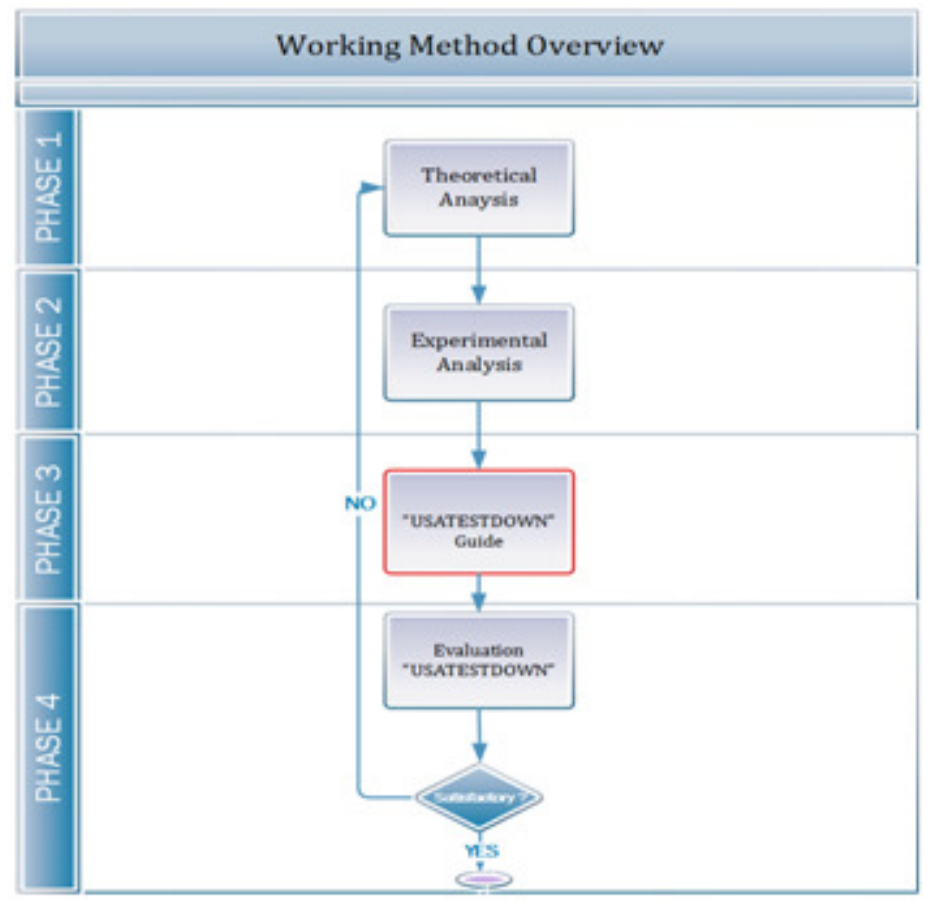

Figure 2: Working Method Overview

- Theoretical analysis. A state of the art on usability testing involving persons with Down syndrome.

- Experimental analysis. There have been made experiments on usability testing with persons with Down syndrome.

- The guideline "USATESTDOWN": This phase consists on the preparation of a guideline to perform usability testing involving persons with Down syndrome. The contents of the guideline, called "USATESTDOWN" are based on the results of phases 1 and 2. The development of the guideline will be iterative. Observational evaluation has been chosen as the method to be used in the usability testing.

- Evaluation of "USATESTDOWN": The USATESTDOWN guideline will be evaluated with a set of experiments involving persons with Down syndrome in usability testing of mobile applications. The results of the evaluation will be used to improve the guideline. 


\subsection{Usability Testing Previous Contributions for Mobile Applications Focused on Persons with Down Syndrome}

The most common method for evaluating how usable a product or system is usability testing, which involves testing prototypes with real users [4]. Participating users are given a set number of tasks that they have to perform using a prototype or a full system. Data on the effectiveness, efficiency and satisfaction of users are collected during testing. Generally, the usability process is divided into the following steps: 1. Recruit participants, 2. Establish the tasks, 3. Write the instructions, 4. Define the test plan, 5. Run the pilot test, 6. Refine the test plan, 7. Run the test session, 8. Analyse the collected objective, and 9. Report results.

We found 5 articles related with our topic after a Literature Review research. We used the definition of the main steps of usability testing [15] to analyse the contributions of each author on each usability testing step. We took the authors contributions in each point [7], [8], [9], [10], [11]. But is important notice they contribute only with the steps $1,2,3,5,7,8$, the steps $4,6,9$ were deleted because there are not contributions. We had the results in table 1 . We can see there are several empty spaces, meaning that there are not contribution in those specific steps.

Table 1 Previous Contributions of Usability Testing

\begin{tabular}{|l|l|l|l|l|l|l|}
\hline Paper & $\mathbf{1 .}$ & $\mathbf{2 .}$ & $\mathbf{3 .}$ & $\mathbf{5 .}$ & $\mathbf{7 .}$ \\
Participants & Tasks & Instructions & Pilot testing & Testing & $\begin{array}{l}\text { 8. } \\
\text { Analyse }\end{array}$ \\
\hline$[10] 2013$ & $\mathrm{X}$ & $\mathrm{X}$ & & & & $\mathrm{X}$ \\
\hline$[13] 2010$ & $\mathrm{X}$ & $\mathrm{X}$ & & $\mathrm{X}$. & $\mathrm{X}$ & \\
\hline$[12] 2011$ & $\mathrm{X}$ & $\mathrm{X}$ & & & & \\
\hline$[11] 2012$ & & $\mathrm{X}$ & & $\mathrm{X}$ & & \\
\hline$[14] 2009$ & $\mathrm{X}$ & $\mathrm{X}$ & $\mathrm{X}$ & & $\mathrm{X}$ & \\
\hline
\end{tabular}

There is not a Guide to evaluate Usability in mobile applications focused on Down syndrome person. Consequently, the authors proposed the need to develop guidelines on the usability testing process in mobile applications involving participants with Down syndrome.

\subsection{Collected Experience}

USATESTDOWN is a guide to support usability testing of mobile applications when the participants are persons with DS. It has been developed by combining information collected from a literature review [15] and experience acquired during four workshops with approximately 100 people with DS [16][17]. We performed several workshops in different Special Dow Syndrome Centre in Spain (Asindown [16], Maria Corredentora [17], Apadema [18], Prodis [19]) as we show in the figure 1. We evaluated 122 persons, 69 children and 53 adults with Down syndrome to determinate the skills, behave and how they interact with mobile devices. 


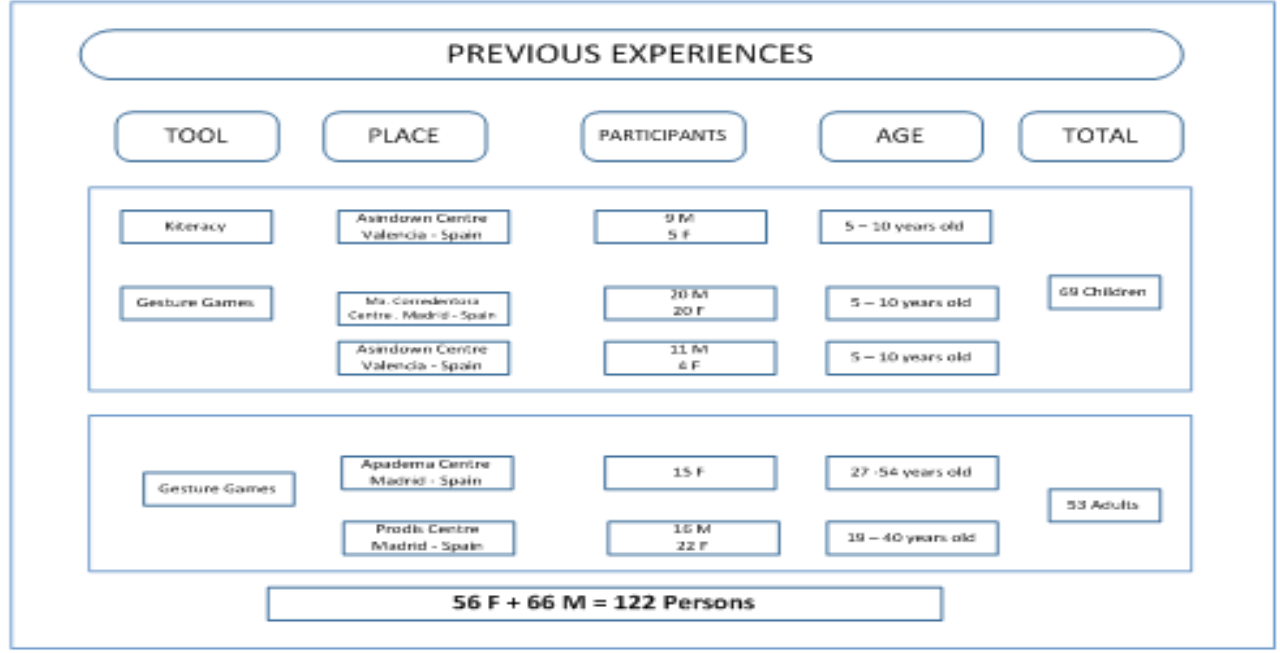

Figure 3: Collected Experience

\section{3. “USATESTDOWN” GUIDE PROPOSAL}

USATESTDOWN is a guide to help usability tests of mobile applications focused on users with Down syndrome. Applying the usability testing guide USATESTDOWN, the evaluators can easily manage the usability test with applications on mobile devices for persons with Down syndrome in the different workshops following the different steps that the guide proposes. We describe the 9 steps of USATESTDOWN recommend for the authors, such as: [23], [24], [25], [24], and [26]. We describe this guide with specific activities in order to evaluate Mobile applications software focused on persons with Down syndrome. The flow of the process was adjusted to account for the reality of the persons with Down syndrome. We showed in Fig, the USATESTDOWN Guide process.

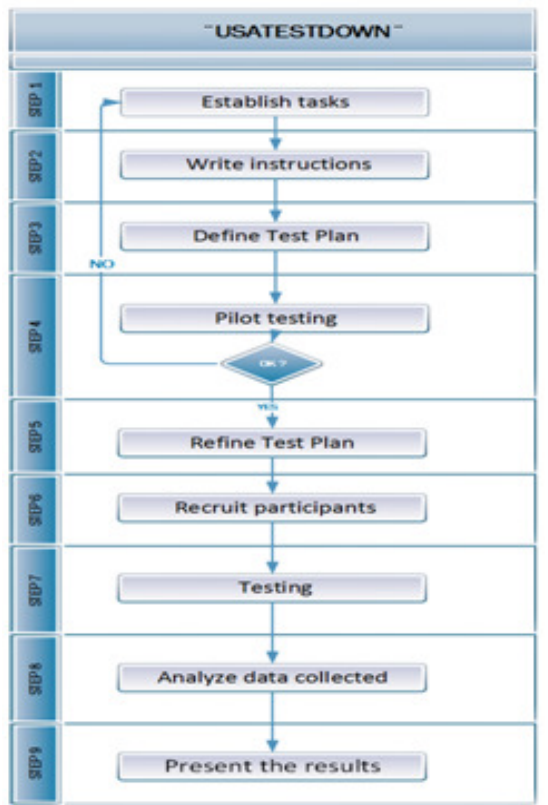

Figure 4: Process of Usability Testing as defined in USATESTDOWN 
After the USATESTDOWN figure scheme we have 9 tables from number II until $\mathrm{X}$ with the following information:

- Definition: According with the authors [18], [19], [20] what we should expect in this point.

- Biography Research: A collection about what the authors propose in this step [7] [8] [9] [10] [11].

- Usatestdown: Contribution of the proposal Guide in order to the experience with the previous workshops realized by the authors

- Documents: Documents to support the step adapted specially to people with DS.

1. Establish the tasks.

Table 2: Usatestdown: Establish the tasks

\begin{tabular}{|c|c|}
\hline \multicolumn{2}{|r|}{ USATESTDOWN } \\
\hline Step: & Establish the tasks \\
\hline Definition & $\begin{array}{l}\text { This step consists of defining the tasks that the participants will complete in the usability tests } \\
\text { should be defined. These tasks will be identified in pre-development phases to identify which } \\
\text { of them will form a part of the evaluation that will include tasks that appear in certain } \\
\text { usability specifications, as well as other representative tasks. }\end{array}$ \\
\hline $\begin{array}{c}\text { Biography } \\
\text { Research }\end{array}$ & $\begin{array}{l}\text { Holds a 30-minute training session [10], takes 20-minute videos per child and uses the } \\
\text { DEVAN method to work directly with children with DS. On the other hand, [13] evaluates a } \\
\text { literacy portal in Africa using the following tasks: submission of evaluation criteria, } \\
\text { submission of document stating procedure to be followed, submission of document on } \\
\text { interfaces and applications for evaluation, signature of anonymity and confidentiality forms. } \\
\text { In the research by [13], the experts identify critical usability problems in the early stages of } \\
\text { the development cycle and divide the evaluation into two phases: acceptance testing and } \\
\text { usability. [14] divides the tasks used in the evaluation into several phases: PHASE 1. Identify } \\
\text { user needs, iteratively engage students in testing, and collect data from teachers and parents } \\
\text { of students with DS, PHASE 2. Conduct the usability evaluation, and PHASE 3. Collect the } \\
\text { data from specialist teachers and parents and hold the scheduled interviews. }\end{array}$ \\
\hline Usatestdown & $\begin{array}{l}\text { - To establish the tasks, it should be considered that they are increased according to a gradual } \\
\text { completion. This is to say that the completed levels will be driven by each individual with } \\
\text { Down's Syndrome due to the fact that they have different levels of abilities and what might } \\
\text { be simple for one may be more complex for others. Therefore, it is necessary that they } \\
\text { determine to which level they will complete. } \\
\text { - The tasks should not be very complex on a difficult scale of } 1 \text { to } 3 \text {, where } 1 \text { is esaier, the } \\
\text { thask dhould take } 1 \text {, } \\
\text { - The session should be done in } 10 \text { minute sessions for each person, because they will get } \\
\text { tired easlily. This point will allow the individual to evaluate the application with curiosity } \\
\text { without getting overwhelmed or bored. } \\
\text { - Do not limit the time. The participants will stress and become confused if they have a time } \\
\text { limit for the task. We could see on the sesions that the participants were getting afraid with } \\
\text { the topic task limited with time. They could feel nervous. }\end{array}$ \\
\hline
\end{tabular}


2. Write the instructions

Table 3: Usatestdown : Write the instructions

\begin{tabular}{|c|l|}
\hline \multicolumn{2}{|c|}{ USATESTDOWN } \\
\hline Step : & \multicolumn{1}{c|}{ Write the instructions } \\
\hline Definition & Specify the instructions given to the users (oral, written, or both) to complete each task \\
\hline Research: & $\begin{array}{l}{[14] \text { describe the instructions for identifying the needs of users, which are collect data, }} \\
\text { interview students' paediatrician and primary school teachers, interact socially with students; } \\
\text { identify the learning needs. Understand the problems through conversations with parents; } \\
\text { interview specialists, teachers and parents as informers on the background of students and the } \\
\text { research. }\end{array}$ \\
\hline Usatestdown & $\begin{array}{l}\text { - Before completing the test, it is necessary to give a presentation to the people who will } \\
\text { participate with the evaluation. They should interact with the aplication on a training way. } \\
\text { The Facilitator should explain the project objectives and he must to ask if the participant } \\
\text { would like to participate even if the Tutor recomeded this participant. The willingness of } \\
\text { the participants to participate is very important because the results depend upon it. } \\
\text { - Task scenarios for this usability test will be based on the tool and taking on count the } \\
\text { participants number } \\
\text { - Observation method needs facilitator to record all children action, behaviours and facial } \\
\text { expressions while observing children playing the game. In order to guide facilitator, an } \\
\text { observation checklist is needed to analyse the participants behavoiur. }\end{array}$ \\
\hline
\end{tabular}

3. Define the test plan

Table 4: Usatestdown: Define the test plan

\begin{tabular}{|c|c|}
\hline \multicolumn{2}{|r|}{ USATESTDOWN } \\
\hline Step : & Define the test plan \\
\hline Definition & $\begin{array}{l}\text { It is necessary to specify the protocol with alternative activities, such as, welcome, } \\
\text { interview preview, completing the tasks by observing the user, satisfaction questionnaire, } \\
\text { personal interview to collect qualitative information, etc. It is recommended to write an } \\
\text { introductory commentary to express a welcome to the users. It is necessary, as part of } \\
\text { these instructions, to collect the data needed by the users to complete the tasks. }\end{array}$ \\
\hline $\begin{array}{l}\text { Biography } \\
\text { Research: }\end{array}$ & NO CONTRIBUTIONS \\
\hline Usatestdown & $\begin{array}{l}\text { - It is necessary to complete a demographic survey including name, age, gender, } \\
\text { experience with mobile devices. It must to have only general information, even it } \\
\text { could use a fake name because family, tutors and participants are so reserved wit } \\
\text { information that it would allow them to be identifier. Never take last names. Don't } \\
\text { push the people to answer if they don't want, it may generate a bad atmosphere to } \\
\text { work. This is like the test that was used in the workshops and can be found in Annex } 1 \text {. } \\
\text { It should be completed by the evaluator. } \\
\text { - It is important to prepare a user satisfaction survey with a scale of no greater than } 3 \\
\text { categories and, if possible, with graphics of faces (happy, neutral, sad). We tried wit } 5 \\
\text { answers but it was confusing to the participants. Aditionally we had a meeting with the } \\
\text { students psicologist supervisors and they also recommended only } 3 \text { levels. } \\
\text { - Avoid providing documents with long text to the people who will participate in the test } \\
\text { Generally, people with DS have vision problems and it is taxing for them to read and } \\
\text { speak. It is recommended that the instructions be given verbally and in a graphic form } \\
\text { that is simple, allowing them to understand the information. In the first workshop } \\
\text { session, we wrote test to explain to the participants the steps that they should follow } \\
\text { but they had probles to read or pronunce and to understand. It si better to avoid } \\
\text { - Write short questions only with } 3 \text { answers (not, may be, yes), in this specific order }\end{array}$ \\
\hline
\end{tabular}




\begin{tabular}{|c|c|}
\hline & 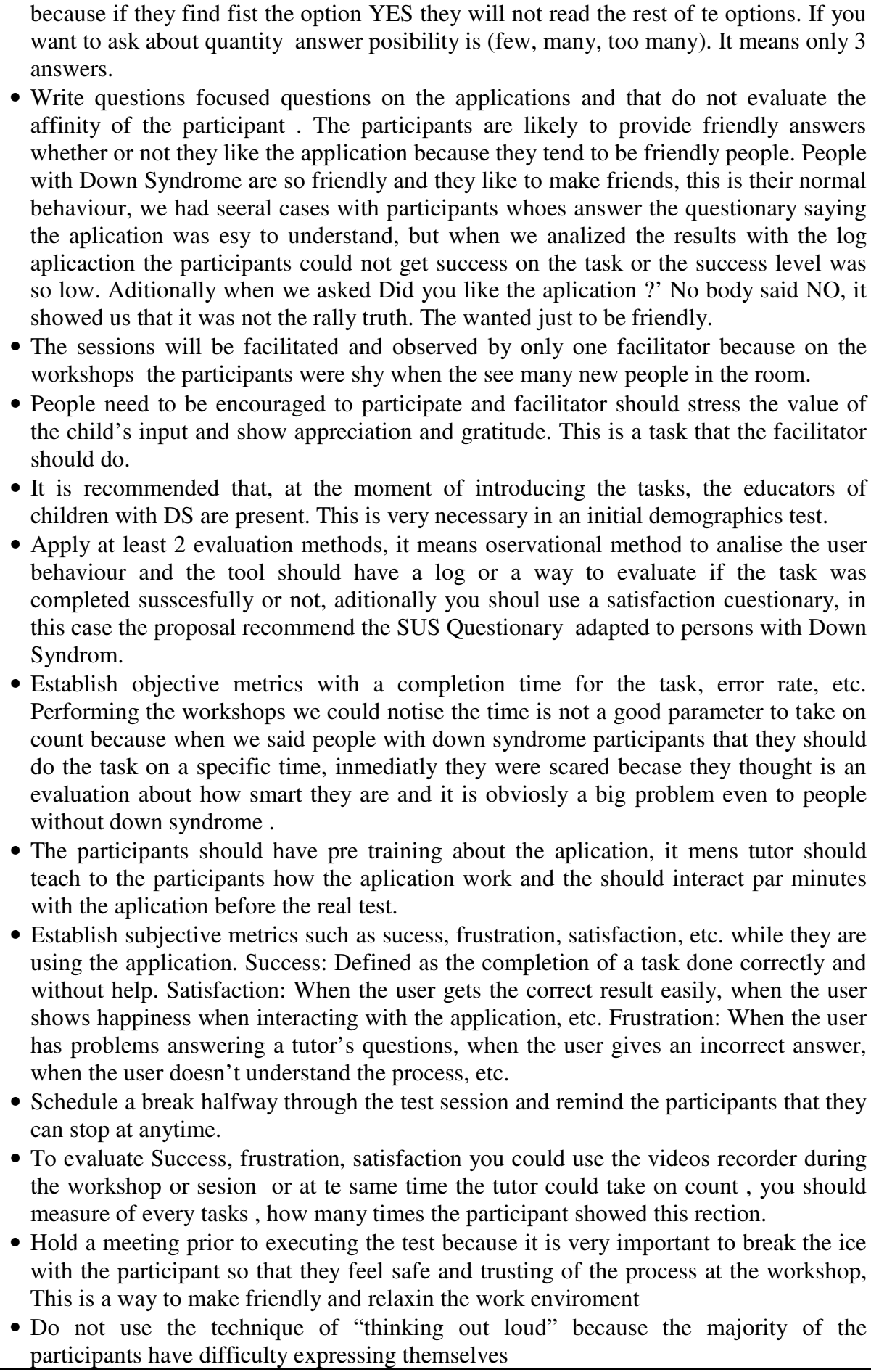 \\
\hline Documents & $\begin{array}{l}\text { The documents should be printed } \\
\text {-UsatestDown Demographic Questionary (Annexes) } \\
\text {-UsatestDown SUS Questionary adapted to people with Down Syndrome focused in the } \\
\text { whole process } \\
\text {-UsatestDown SUS Questionary to Tutors focused in the whole process (Annexes ) }\end{array}$ \\
\hline
\end{tabular}




\section{Run the pilot test}

Table 5: Usatestdown: Run the pilot test

\begin{tabular}{|c|c|}
\hline \multicolumn{2}{|r|}{ USATESTDOWN } \\
\hline Step : & Run the pilot test \\
\hline Definition & $\begin{array}{l}\text { Execute the test protocol using the welcome, the written instructions, completing the } \\
\text { observations, measuring times, completing the interviews, etc. in order to analyze if the } \\
\text { proposed process functions as expected. In the case that it is not, it should be writen as the } \\
\text { protocol describe. }\end{array}$ \\
\hline $\begin{array}{l}\text { Biography } \\
\text { Research: }\end{array}$ & $\begin{array}{l}\text { F. Adebesin et al. [13] conducted a pilot test aimed at understanding how applications work. } \\
\text { L. Kumin and J. Lazar,[11] believe formal data collection to be important for the pilot test. } \\
\text { This should be followed by a second session during which they suggest modifying the list of } \\
\text { tasks, adding a warm-up task. }\end{array}$ \\
\hline Usatestdown & $\begin{array}{l}\text { - Record in video the interaction of the person with the mobile device. It is recommended } \\
\text { and very important in order to qualitatively evaluate their interaction with it when we } \\
\text { review the videos. Be careful not to film faces and to obtain authorization in order to } \\
\text { complete this point. } \\
\text { - Ask for permission if it is necessary to film faces,but evaluator should be really polite } \\
\text { because this is a sensitive topic. Some times is necessary the fathers autorization to record } \\
\text { participants faces . } \\
\text { - It is recommended that the pilot test is done through a small samples but in this case it } \\
\text { means only one person because the evaluator will notice with the second participant the } \\
\text { mistake will be the same. This will allow a definition of the first process errors without } \\
\text { needing to involve all of the participants in the process, repeating the same error. } \\
\text { - During the entire evaluation process or user participation, it is necessary that the tutors or } \\
\text { professors with whom they are interacting on a daily basis are present and provide a sense } \\
\text { of support as we could see in the sessions we performed. } \\
\text { - The facilitator will sit next to the child during the session and his/her role is to fill in the } \\
\text { observation form while interacting with the child to make them feel at ease. We rocomend } \\
\text { the participant doesnot write himself the questionary. They use to have problems to write } \\
\text { or read. } \\
\text { - There are two questionnaires that need to be assessed which are demographic } \\
\text { questionnaire and post task questionnaire but we propose specifics questionaies adapted to } \\
\text { participants with Down Syndrome. We designed this questionaries with Special } \\
\text { Psicologist whoes work every day with those participants , taking as base the SUS } \\
\text { - Puestionarie. } \\
\text { Post task questionnaire will be conducted right after each test session with the help from } \\
\text { - The Tutor or Parent. Facilitador should be close just in case the participant have a dubt. } \\
\text { - Use simple words when directing the participants. When you explain to the participants } \\
\text { the tasks, process, objectives etc, you should use a esy vocabulary and you must to speak } \\
\text { can stop at anytime. }\end{array}$ \\
\hline Documents & $\begin{array}{l}\text { The documents should be applied } \\
\text {-UsatestDown Demographic Questionary (Annexes) } \\
\text {-UsatestDown SUS Questionary adapted to people with Down Syndrome focused in the } \\
\quad \text { whole process } \\
\text {-UsatestDown SUS Questionary to Tutors focused in the whole process (Annexes ) }\end{array}$ \\
\hline
\end{tabular}


5. Refine the test plan after analysing the results of the pilot tests.

Table 6: Usatestdown: Refine the test plan after analyzing the results of the pilot tests.

\begin{tabular}{|c|c|}
\hline \multicolumn{2}{|r|}{ USATESTDOWN } \\
\hline Step : & Refine the test plan after analysing the results of the pilot tests. \\
\hline Definition & $\begin{array}{l}\text { Once analyzing the results of the pilot test, modifications may be made to the protocol, } \\
\text { instructions, task data, task sequencing, interview questions, etc., if necessary. }\end{array}$ \\
\hline $\begin{array}{l}\text { Biography } \\
\text { Research: }\end{array}$ & NO CONTRIBUTIONS \\
\hline Usatestdown & $\begin{array}{l}\text { If an error is encountered in the test pilot, it is necessary to make an immediate change to } \\
\text { the plan and execute a second session. } \\
\text { The appropriate corrections should be taken. }\end{array}$ \\
\hline
\end{tabular}

6. Recruit participants

Table 7: Usatestdown: Recruit participants

\begin{tabular}{|l|l|}
\hline \multicolumn{1}{|c|}{ USAep : } & \multicolumn{1}{c|}{ Recruit participants } \\
\hline Definition & Process to determine the type and number of participants needed for the usability tests. \\
\hline Research: & $\begin{array}{l}\text { From the analysis of the research with regard to the recruitment of participants, we find that } \\
\text { [10] take four children aged from } 6 \text { to } 12 \text { years with DS, [13] use five usability experts and } \\
\text { six learners, [12] use from three to five interface design and learning content experts, and } \\
\text { [20] work with two paediatricians, primary school teachers and 11 children with DS. This } \\
\text { illustrates the importance of working with on average 10 paediatricians, interface and } \\
\text { learning content evaluators and people with DS. The activities specified by [11] are validate } \\
\text { the criteria for recruiting participants, like computer experience. Nielsen's study showed } \\
\text { that a group of five users with different background, mixed gender and aged five to six } \\
\text { years old, they were able to find about 80\% of the findings in a system. }\end{array}$ \\
\hline $\begin{array}{l}\text { Usatestdown } \\
\text { The first step in recruiting young participants is sending information about the study to } \\
\text { the places whoes are working with the particpants profile that we want to work, it means, } \\
\text { - Tutor should recommend the particcipants proffile because the mental age is different } \\
\text { than the bilogical age. We should not only take on count the participants age, we should } \\
\text { analize what are the especial skils that every participant have. In our case at the beginning } \\
\text { we found participants with low mental dishabilities and another so extrem. It makes not } \\
\text { homogeneous group because we were not evaluating really the aplication, we were } \\
\text { evaluating just the cognitive disabilities. } \\
\text { - The facilitator should ask the participant if he/she wants to colaborate because the } \\
\text { participant should be voluntier. We had a case with a participant who behaved on a rude } \\
\text { way . We asked him if he want to participate and he did not want. It is the best way to } \\
\text { evaluate because some times they feel pushed to contribute. } \\
\text { Don't push them to finish fast. }\end{array}$ \\
\hline
\end{tabular}


7. Run the test session

Table 8: Usatestdown: Run the test session

\begin{tabular}{|c|c|}
\hline \multicolumn{2}{|r|}{ USATESTDOWN } \\
\hline Step : & Run the test session \\
\hline Definition & $\begin{array}{l}\text { This is the essential part of the evaluation because it is here that the usability evaluation } \\
\text { is completed. (1) Welcome; (2) Ask the participants to carry out the tasks; ( } 3 \mathrm{a}) \text { If } \\
\text { performance is measured, measure the times, (3b) If performance is not measured, } \\
\text { interrupt the user to clarify their decisions; (4) Note the number of errors and other } \\
\text { objective data; (5) Distribute a satisfaction questionnaire and complete a personal } \\
\text { interview. }\end{array}$ \\
\hline $\begin{array}{l}\text { Biography } \\
\text { Research: }\end{array}$ & $\begin{array}{l}\text { [14] collect the data iteratively from people with DS in Phase } 1 \text {. Another aim is identify } \\
\text { the suitability of the teaching material for the learning problems that students are set. } \\
\text { [13] describe the testing steps: execute evaluation, write report, submit report to } \\
\text { immediate evaluator, okay report, and compile evaluation reports. }\end{array}$ \\
\hline Usatestdown & $\begin{array}{l}\text { - Do not complete the final test on the same day as the pilot testing because the users } \\
\text { will be tired and confused if the first pilot process failed. } \\
\text { - It is recommended to execute the complete test from the beginning, including the } \\
\text { changes that were made to the test plan after the pilot. } \\
\text { - Consider the reactions of the people being evaluated for each of the tasks that they } \\
\text { complete. It is very important to determine their satisfaction level and the } \\
\text { improvements that could be made in the next version. } \\
\text { - Solve all of the questions that the user has during the process. } \\
\text { - After completing the usability test session with a down syndrome participant, } \\
\text { facilitator needs to ask the child to answer post task questionnaire. } \\
\text { - Take note of the times when the participant asks for help. } \\
\text { - Don't push the people to participate if they don't want, it may generate a bad } \\
\text { atmosphere to work. } \\
\text { - Don't push the people to answer if they don't want, it may generate a bad atmosphere } \\
\text { - Uo work. } \\
\text { pse simple words when directing the participants. When you explain to the } \\
\text { - Sou must to speak } \\
\text { - Take note of the times when the participant asks for help. } \\
\text { - Schedule a break halfway through the test session and remind the participants that they } \\
\text { can stop at anytime. }\end{array}$ \\
\hline Documents & $\begin{array}{l}\text {-UsatestDown Demographic Questionary (Annexes) } \\
\text {-UsatestDown SUS Questionary adapted to people with Down Syndrome focused in the } \\
\quad \text { whole process } \\
\text {-UsatestDown SUS Questionary to Tutors focused in the whole process (Annexes ) }\end{array}$ \\
\hline
\end{tabular}


8. Analyse the collected information

Table 9: Usatestdown: Analyze the collected information

\begin{tabular}{|c|c|}
\hline \multicolumn{2}{|r|}{ USATESTDOWN } \\
\hline Step : & Analyse the collected information \\
\hline Definition & $\begin{array}{l}\text { Analyze the objective data (times, errors, etc.), the more subjective data (satisfaction } \\
\text { questionnaire and interviews), and all of the data that contributes to understanding the } \\
\text { behavior of the evaluated people from the usability test. The objective is to identify } \\
\text { usability problems and propose improvements. }\end{array}$ \\
\hline $\begin{array}{l}\text { Biography } \\
\text { Research: }\end{array}$ & $\begin{array}{l}\text { The DEVAN method is based on the structured analysis of video material captured } \\
\text { during user tests and was developed to detect usability problems in task-based products } \\
\text { for adults. When used for evaluation with children, this method can be adjusted for the } \\
\text { detection of usability and fun problems [21]. }\end{array}$ \\
\hline Usatestdown & $\begin{array}{l}\text { - It is important to analyze the data with all of the parameters collected from the } \\
\text { people who participated in the usability test. This involves qualitative content (logs) } \\
\text { as well as quantitative (user reactions). } \\
\text { - Conduct an analysis of the part that appeared qualitatively in the evaluation and the } \\
\text { quantitative data results. } \\
\text { It is not always the same result. } \\
\text { - The tool should take the time automatically. } \\
\text { - The tool should help the evaluation. } \\
\text { - Success, Satisfaction and Frustration Rate per Task and Document } \\
\text { - This includes; the people feeling, fun, ease of use and their satisfaction level } \\
\text { - } \quad \text { Data are collected while observing the child performing the task scenarios. }\end{array}$ \\
\hline
\end{tabular}

9. Report results to the development team or management.

Table 10: Usatestdown: Report results to the development team or management.

\begin{tabular}{|c|c|}
\hline \multicolumn{2}{|r|}{ USATESTDOWN } \\
\hline Step: & Report results to the development team or management. \\
\hline Definition & $\begin{array}{l}\text { Prepare a presentation or report to explain the usability problems that were encountered } \\
\text { and how they can be improved. }\end{array}$ \\
\hline $\begin{array}{l}\text { Biography } \\
\text { Research: }\end{array}$ & NO CONTRIBUTIONS \\
\hline Usatestdown & $\begin{array}{l}\text { - The results presentation should be done with all of the members of the group, with a } \\
\text { clear document, and with the respective backups. } \\
\text { - -In the case that the results were not satisfactory, improvements to the system should } \\
\text { be made and it should be executed again, following the USA TESTDOWN guide. } \\
\text { - Apply the Ethical Issues in Recruiting Participants, it means follow the rules that each } \\
\text { centre have to manage the participant information with ethical process. We should safe } \\
\text { in a private and confidential way the collected information } \\
\text { - In the Maria Corredentora [22] case, we did a inform with the most important points } \\
\text { because they use this information to improve the way to teach. }\end{array}$ \\
\hline
\end{tabular}




\section{CONCLUSIONS AND FUTURE WORK}

In general, we can see that it was necessary to adapt the SUS questionnaire for the persons with Down syndrome because it is a complex survey for participants. SUS was modified to evaluate the USATESTDOWN process, the guide, which was designed with the expert tutors who work with the participants daily.

In general, it is clear that the guide is viable and can be successfully used and modified to the needs of persons with Down syndrome, with this as an example of a real-world success. It was also evaluated by the expert tutors as part of this process, which was a great help and supported the adaptation of the guide. The participation of the expert tutors is very important as their experience greatly contributed to the implementation of the test, following the guide. Additionally, it is critically important to include the expert tutors with the interaction with the participants'

It is necessary also the previous interactions with the application to create a comfortable and familiar environment so the participants feel safe and trust the process as they are asked questions or doing a task. We recommend that times are not as strict and participants are able to work with as much flexibility as possible. The time parameter set by the first participant to force the second participant to complete the task in the same amount of time was not always produce the same cognitive or memory coefficients.

We suggest an evaluation stage where devices are given back to them to determine how much time is necessary for them to work independently from the tutors and then independent of the application and able to do the activity without the support of a tutor or the application.

\section{REFERENCES}

[1] J. Jadán-Guerrero, L. Guerrero, G. López, D. Cáliz, and J. Bravo, "Creating TUIs Using RFID Sensors-A Case Study Based on the Literacy Process of Children with Down Syndrome," Sensors, vol. 15 , no. 7 , pp. 14845-14863, 2015.

[2] L. M. Normand, "No Title."

[3] A. Brandão, E. Passos, C. Vasconcelos, A. Conci, E. Clua, P. T. Mourão, and M. Cordeiro, "Stimulating imitation of children with Down syndrome using a game approach," VIII Brazilian Symp. Games Digit. Entertain., pp. 97-100, 2009.

[4] J. R. Joseph S. Dumas, A Practical Guide to Usability Testing. .

[5] A. Lepistö, "Usability evaluation involving participants with cognitive disabilities," Proc. third Nord. Conf. Humancomputer Interact. Nord. 04, pp. 305-308, 2004.

[6] J. Nielsen and M. Kaufmann, “Usability Engineering,” p. 340, 1993.

[7] J. Nielsen, "Heuristic Evaluation," Usability Insp. Methods, pp. 25-62, 1994.

[8] A. Brand??o, D. G. Trevisan, L. Brand??o, B. Moreira, G. Nascimento, C. N. Vasconcelos, E. Clua, and P. T. Mour??o, "Semiotic inspection of a game for children with Down syndrome," Proc. - 2010 Brazilian Symp. Games Digit. Entertain. SBGames 2010, no. August 2016, pp. 199-210, 2011. 
[9] R. Pal, "On the Lewis-Nielsen model for thermal/electrical conductivity of composites," Compos. Part A Appl. Sci. Manuf., vol. 39, no. 5, pp. 718-726, 2008.

[10] I. Macedo and D. G. Trevisan, "A Method to Evaluate Disabled User Interaction : A Case Study with Down Syndrome Children," Univers. Access Human-Computer Interact. Des. Methods, Tools, Interact. Tech. eInclusion, pp. 50-58, 2013.

[11] L. Kumin and J. Lazar, "A Usability Evaluation of Workplace-Related Tasks on a Multi-Touch Tablet Computer by Adults with Down Syndrome,” J. Usability ..., vol. 7, no. 4, pp. 118-142, 2012.

[12] R. Ramli and H. B. Zaman, "Designing usability evaluation methodology framework of Augmented Reality basic reading courseware (AR BACA SindD) for Down Syndrome learner," Proc. 2011 Int. Conf. Electr. Eng. Informatics, ICEEI 2011, no. July, 2011.

[13] F. Adebesin, P. Kotzé, and H. Gelderblom, "The complementary role of two evaluation methods in the usability and accessibility evaluation of a non-standard system," Proc. 2010 Annu. Res. Conf. South African Inst. Comput. Sci. Inf. Technol. - SAICSIT '10, pp. 1-11, 2010.

[14] R. L. Yussof and H. Badioze Zaman, "Usability evaluation of multimedia courseware (MEL-SindD)," Lect. Notes Comput. Sci. (including Subser. Lect. Notes Artif. Intell. Lect. Notes Bioinformatics), vol. 5857 LNCS, pp. 337-343, 2009.

[15] D. Cáliz, L. Martínez, X. Alamán, C. Terán, and R. Cáliz, “ U Sability Testing in Mobile Applications Involving People With Down Syndrome : a Literature Review ," ICAIT 2016 Conf., 2016.

[16] Asindown ORG, “Asindown Valencia," 2017. [Online]. Available: http://asindown.online/. [Accessed: 10-Jan-2017].

[17] M. Corredentora, "Ma. Corredentora," 2017. [Online]. Available: http://mariacorredentora.org/wpmcorg/. [Accessed: 10-Jan-2017].

[18] A. ORG, “Apadema,” 1971. [Online]. Available: http://www.apdema.org/tag/madrid/.

[19] "Fundación PRODIS," 2016. [Online]. Available: http://www.fundacionprodis.org/. [Accessed: 14Jun-2016].

[20] R. L. Yussof and T. N. S. T. Paris, "Reading Activities Using the Scaffolding in MEL-SindD for Down Syndrome Children,” Procedia - Soc. Behav. Sci., vol. 35, no. December 2011, pp. 121-128, 2012.

[21] J. Marco, E. Cerezo, and S. Baldassarri, "Bringing tabletop technology to all: Evaluating a tangible farm game with kindergarten and special needs children," Pers. Ubiquitous Comput., vol. 17, no. 8, pp. 1577-1591, 2013.

[22] "Maria Corredentora Centre," 2016. [Online]. Available: http://mariacorredentora.org/wpmcorg/ . [Accessed: 11-Nov-2016]. 


\section{AUTHORS}

\section{Ing. MSc. Doris Cruz Caliz Ramos.}

- Computer Sciences Engineering

- Master in Management of Information Technology and Communications National

- Polytechnic School Ecuador. 2008 - 2012

- International Leadership Training. Germany. 2011 - 2012

- $\quad$ PHD Student in Polytechnic School Madrid. 2013- 2017

- Academic Visitor in Middlesex University London. 2015 - 2016

- Academic Visitor Karlsruhe Institute of Technology (KIT). Pervasive Computing Systems - TecO

\section{Doctor. Loic Antonio Martinez Normand}

- Professor Department ETSIINF, DLSIIS, Madrid Polytechnic University. 2008 - Today.

- Researcher in Group Investigation on Technology Informatics and Communications: CETTICO.

- President Sidar Foundation. 2002 - Today
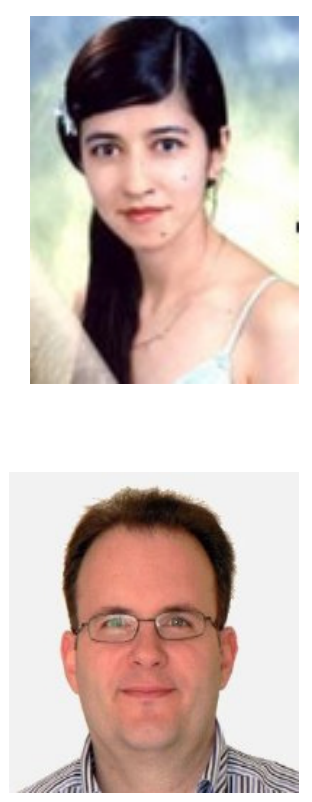

Ing.MSc. Richarth Harold Caliz Ramos.

- Master in Management of Information Technology and Communications MSc, final mark: cum laude. National Polytechnic School (EPN), Quito, Ecuador (Fall 2008-Winter 2010)

- Telecommunications and Electronics Enineering, final mark: cum laude. National Polytechnic School (EPN), Quito, Ecuador (Fall 1995-Winter 2002)

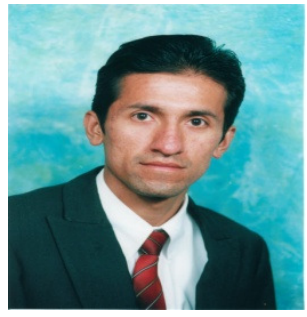

